\title{
Crashed! Why Drone Delivery Is Another Tech Idea not Ready to Take Off
}

\author{
Ngui Min Fui Tom ${ }^{1}$ \\ ${ }^{1}$ Pôle Paris Alternance (PPA), IPE Management School Paris, France; Eramaju Synergy Sdn Bhd, Malaysia \\ Correspondence: Ngui Min Fui Tom, Pôle Paris Alternance (PPA), IPE Management School Paris, France; \\ Eramaju Synergy Sdn Bhd, Kota Kinabalu, Sabah, Malaysia.
}

Received: June 8, 2020

doi:10.5539/ibr.v13n7p251

\author{
Accepted: June 29, 2020 \\ Online Published: June 30, 2020 \\ URL: https://doi.org/10.5539/ibr.v13n7p251
}

\begin{abstract}
The objective of this study was to examine why drone delivery is another tech idea not ready to take off. Qualitative methods, which involved inductive, exploratory and interpretivism approaches, were used in this conceptual study. The inductive approach was used to generate propositions based on secondary data obtained from journal articles, authorized website contents, and books. On the other hand, exploratory and interpretivism approaches were used to undertake in-depth analysis and to have a complete description and understanding of the factors that shape consumers' behavioural intentions to use drone food delivery services, respectively. Based on research findings and news related to consumers' behavioural intentions to use drone delivery services, conceptual frameworks have been proposed to show the four main independent variables, which are functions, hedonic motivation, cognition, and social factors, that affect the dependent variable, which is behavioural intentions of consumers to use drone for food delivery services. Overall, factors that were hindering consumers' behavioural intentions to use drone food delivery services were consumers' unfamiliarity and negative perceptions toward drone delivery in that it is unregulated, dangerous, risky, lack of quantified risk assessments, intimidating, related to military and defence, and lengthy in the process to obtain authority's permission to operate food delivery services by drones. Nevertheless, they may be influenced to use drone delivery if their friends and family were using it.
\end{abstract}

Keywords: functions, hedonic motivation, cognition, social benefits, behavioural intentions, drone delivery, food delivery service

\section{Introduction}

\subsection{Background of the Study}

The methods used in this conceptual study were qualitative methods, which involved inductive, exploratory and interpretivism approaches. The inductive approach was used to generate propositions based on secondary data obtained from journal articles, authorized website contents, and books. On the other hand, exploratory and interpretivism approaches were used to have in-depth analysis and to have a complete description and understanding of the factors related to consumers' behavioural intentions to use drone food delivery services, respectively.

The objective of this conceptual study was to understand the factors that influence consumers' behavioural intentions to adopt drone delivery services. Based on the past research findings, these factors revolved around the functions of drone delivery such as cost and efficiency of the technology and human factors in controlling the drone delivery, hedonic motivation such as security, cognitive pathway that guides consumers' acceptance of using drone delivery such as regulation and land rights, and social benefits of using drone delivery with friends and family (Hwang et al., 2019; Kapser and Abdelrahman, 2020).

Drone, also known as an unmanned aircraft system (UAS), uses the control operation systems at ground level and can be operated without a human pilot onboard (Royo-Vela and Black, 2020). The world's first drone delivery service was offered by Flytrex Sky, an Israeli company founded in 2013, in Iceland in 2015 (JTA, 2017; Macaulay, 2017). The idea of using drone to deliver food was introduced initially to increase the satisfaction of customers, sellers, and drone third party logistic service providers through quick delivery of merchandise like food even in traffic-congested urban cities (Pillai, 2019). In America, to realize the benefits of drones in drone package delivery, 
drone innovation through the Unmanned Aircraft Systems (UAS) Integration Pilot Program (IPP) has to obtain the Federal Aviation Association (FAA) Part 135 air career certificate by proving their concept in drone package delivery (FAA, 2020). To date, drones that have received the Part 135 standard certification are Wing drone from Wing Aviation LLC, a subsidiary of Alphabet Inc., and Matternet M2 drone from Matternet corporation and UPS corporation (Associated Press, 2019; Kim, 2020). While in other parts of the world such as Malaysia as wells as some other countries like the United States of America and Israel, consumers' behavioural intentions in using drone as food delivery services were also increasing with drone delivery trails since 2019 (Ker, 2019; Scutti, 2019; Mark, 2019; Royer, 2019).

Theories that were used to explain the consumers' behavioural intentions to use drone for food delivery services include the Technology Acceptance Model (TAM), Theory of Planned Behaviour (TPB), and Unified Theory of Acceptance and Use of Technology (UTAUT). TAM explains the effects of perceived usefulness and ease of use on consumers' attitudes toward drone food delivery services. TPB is used to predict consumers' behavioural intentions to adopt drone as food delivery services based on their attitudes, subjective norms, and perceived behavioural control. While UTAUT emphasizes the influences of performance expectancy, effort expectancy, social influences, facilitating conditions, and demographic factors of consumers on their behavioural intentions to use drone as food delivery services (Khan et al., 2019; Ramadan et al., 2017; Dejonghe, 2019).

\subsection{Development of Behavioural Intentions to use Drone Food Delivery Services}

Before the commercial applications, the drone was only used for military and recreational purposes. However, in America, drone sales increased 224\% in the period between April 2015 and April 2016 due to the amendment of FAA requirements on drone operators and producers (Royo-Vela and Black, 2020). Also, even though e-commerce has brought convenience like rapid delivery, consumers may turn to drone as food delivery services due to the increasing consumers' awareness of environmental side effects from e-commerce (Dost and Maier, 2018). Moreover, businesses worldwide are emphasizing more and more on customer engagement as engaged customers will bring more sales and revenue as compared to the disengaged customers and hence, enhancing customer experience becomes the top priority. The drone food delivery service was one of the methods to accommodate and fulfil customers' ever-growing demands in delivery time (Kumar et al., 2019). For instance, in Korea, multiple food service companies have already adopted drone for food delivery services including Yogiyo, which is one of the largest food delivery service companies in Korea (Hwang and Kim, 2019). Currently, there are 21 corporations from different industries using drone delivery technology including Amazon, Alphabet, FedEx, Uber, Microsoft, Facebook, Apple, IBM, Bechtel, DHL, Walmart, Balfour Beatty, EasyJet, UPS, JD.com, GE, Shell, Allstate, BBC, Intel, and USAA (CBI, 2020).

Apart from an Iranian military general killed in the drone strike authorized by Donald Trump, the President of United States of America, on January $3^{\text {rd }}, 2020$ (The Guardian, 2020; Dilanian and Kube, 2020), there was no known major disruptive impact of drone food delivery services to social and political relations (Elliott, 2019). Overall, drone delivery was economically-viable as merchants can drastically reduce the labour and transportation cost while making sure customers can receive their product in a short period (Pillai, 2019). On the other hand, consumers deemed drone delivery as an innovative service and effort from merchants to meet their needs even though they were unhappy and anxious about the outfitting of drones with hazardous material as echoed by both military forces and political leaders alike (Hwang et al., 2019; Jackman, 2019).

\subsection{Challenges of Behavioural Intentions to use Drone Food Delivery Services}

General public perception of drone food delivery services was on the negative side in that it is unregulated, dangerous, and risky (CAA, 2016). The fear, anxiety, or concern over the erosion of one's rights due to the lack of quantified risk assessments on drone delivery was hindering people from using drone for food delivery services (Zwickle et al., 2019). Besides, regulations focusing on protecting consumer privacy and security have been minimal, putting consumers' safety at risk (Chang et al., 2017). The fact that the drone was heavily related to military and defence in the past, for instance, the drone attack on an airport in Saudi Arabia that killed one person and wounded seven has influenced the consumers' perceived risk in drone as food delivery services and caused negative emotions like unhappiness, anxiety, or frustration in the consumers (Chan, 2019; Hwang and Choe, 2019; Jackman, 2019). Furthermore, permission from the public authority is required for a drone to fly above highways is also time-consuming (Dejonghe, 2019). All the above-mentioned challenges hindered consumers' behavioural intentions to use drone as food delivery services. Hence, this study was to investigate the factors influencing the consumers' behavioural readiness to adopt food delivery by drones. 


\section{Literature Review}

\subsection{Theories}

2.1.1 Technology Acceptance Model (TAM)

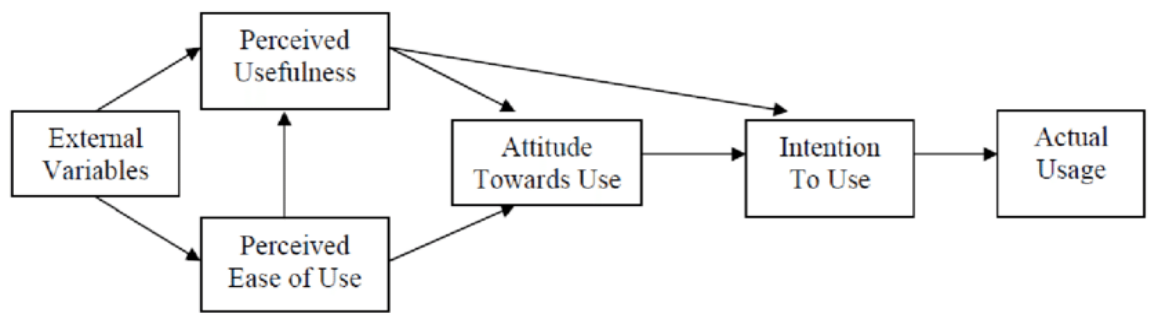

Figure 1. Technology Acceptance Model (TAM)

(Source: Davis et al., 1989)

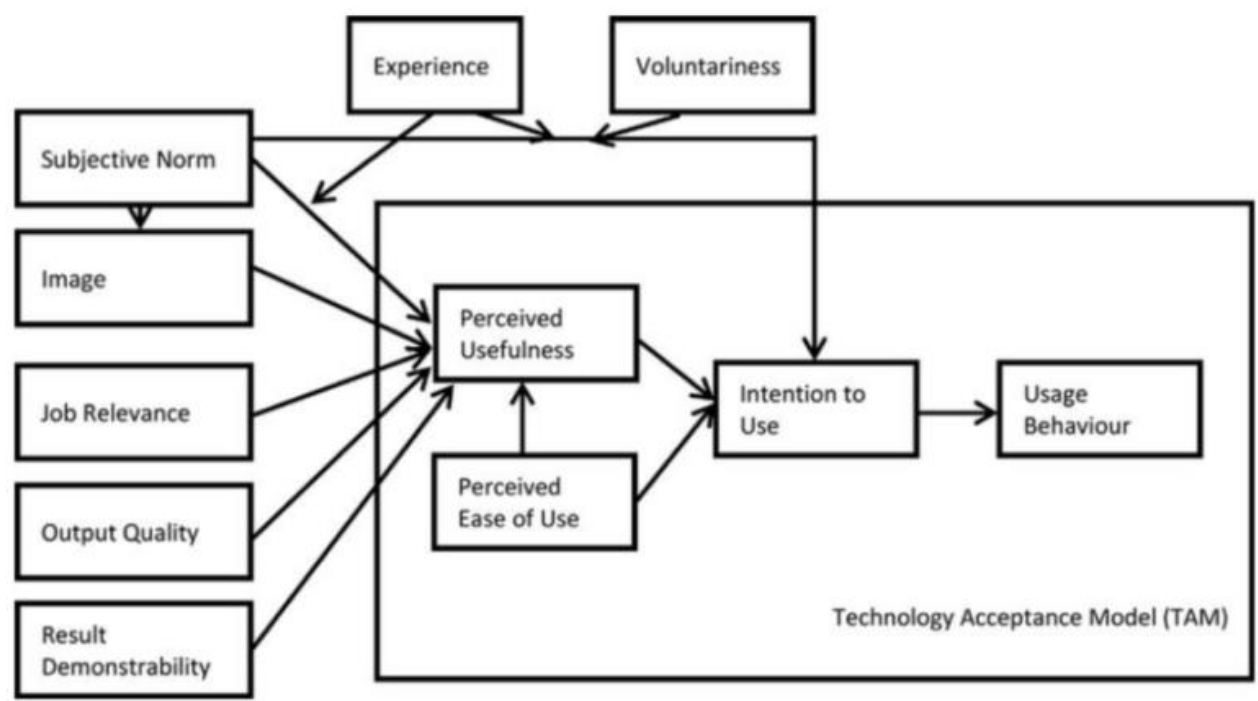

Figure 2. Extended Technology Acceptance Model (TAM)

(Source: Venkatesh and Davis, 2000)

TAM explains the effects of the perceived ease of use and usefulness on consumers' behavioural intentions or attitudes towards innovations like drone delivery (Davis et al., 1989; Figure 1). It has evolved which led to the extended TAM with added specific external variable factors, which included subjective norms, image, job relevancy, output quality, and result demonstrability that specifically affect the perceived usefulness, and moderating factors like experience and voluntariness (Venkatesh and Davis, 2000; Figure 2). 


\subsubsection{Theory of Planned Behaviour (TPB)}

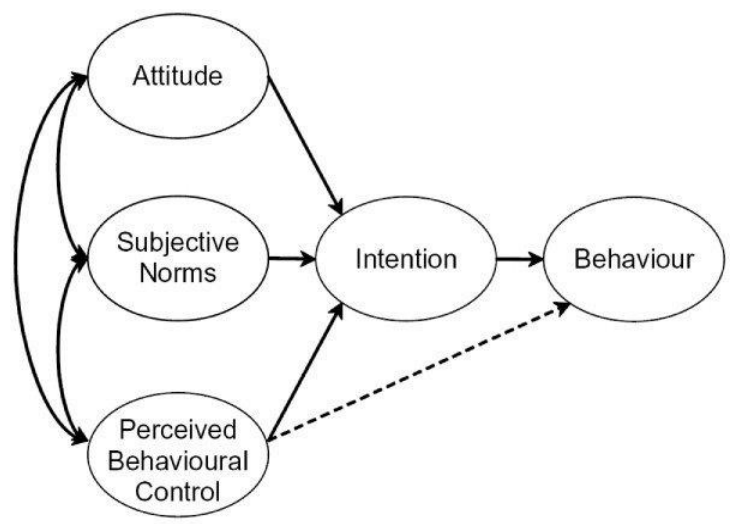

Figure 3. Theory of Planned Behaviour (TPB)

(Source: Ajzen, 1991)

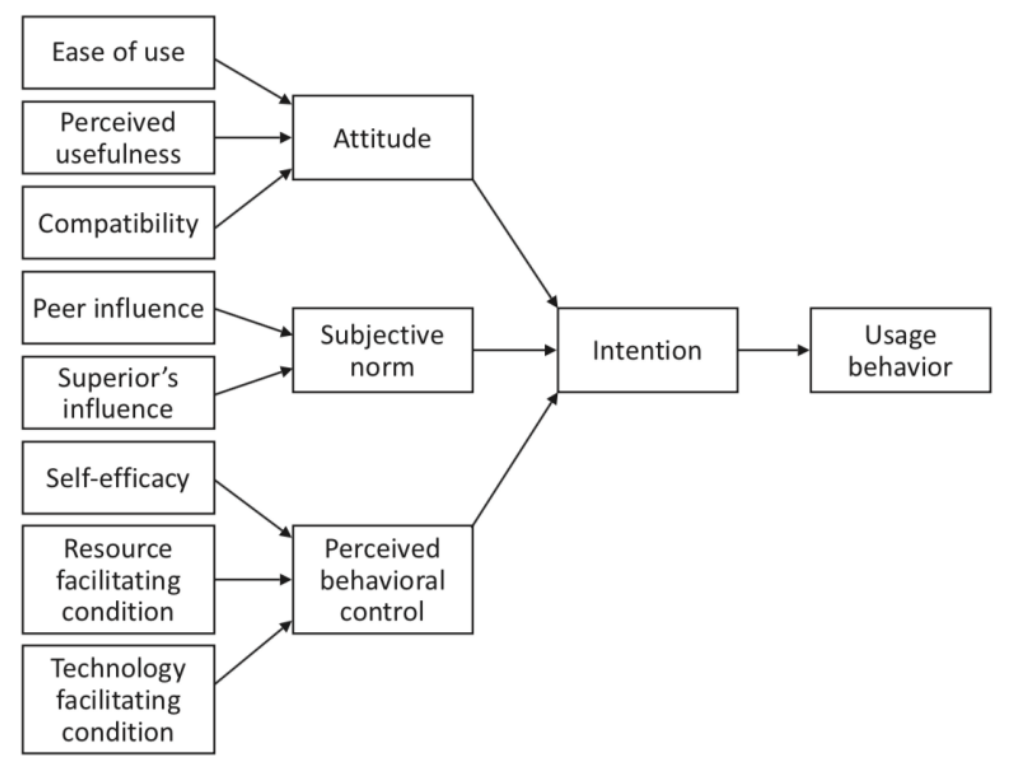

Figure 4. Decomposed Theory of Planned Behaviour (DTPB)

(Source: Taylor and Todd, 1995)

TPB explains the effects of consumers' attitudes, subjective norms, and perceived behavioural control on consumers' intentions to use drone delivery (Khan et al., 2019; Figure 3). Even though TPB was extensively used to predict consumers' behaviour towards a particular product, it is suitable only for products that are already on the market. Hence, Taylor and Todd (1995) modified the existing TPB framework and formed the Decomposed Theory of Planned Behaviour (DTPB), which is suitable for new technology innovations like drone delivery. Factors that will affect consumers' attitudes, subjective norms, and perceived behavioural control have been added to the DTPB framework (Taylor and Todd, 1995; Chawinga and Zinn, 2016; Figure 4). 


\subsubsection{Unified Theory of Acceptance and Use of Technology (UTAUT)}

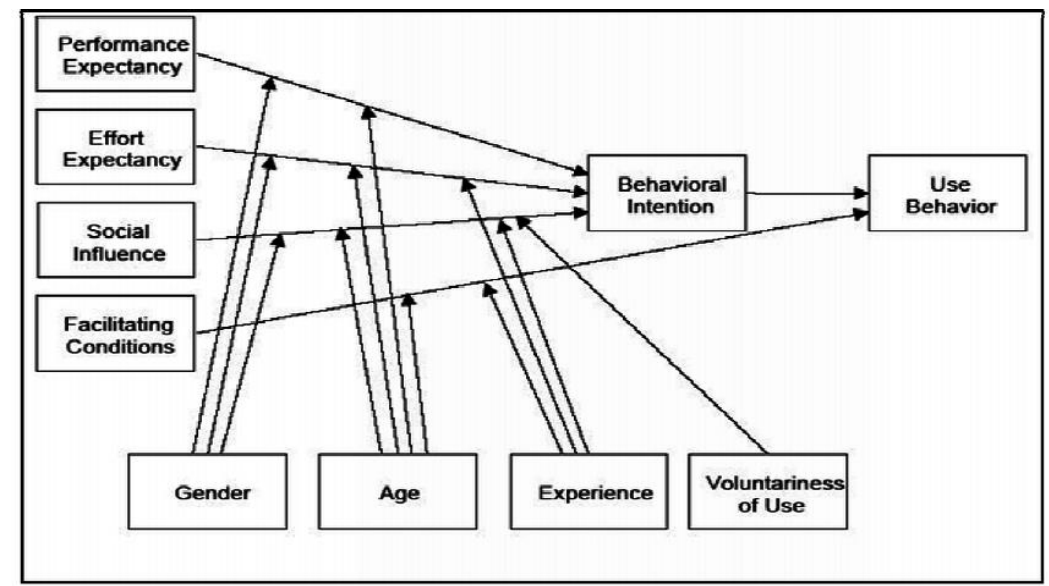

Figure 5. Unified Theory of Acceptance and Use of Technology (UTAUT)

(Source: Venkatesh et al., 2003)

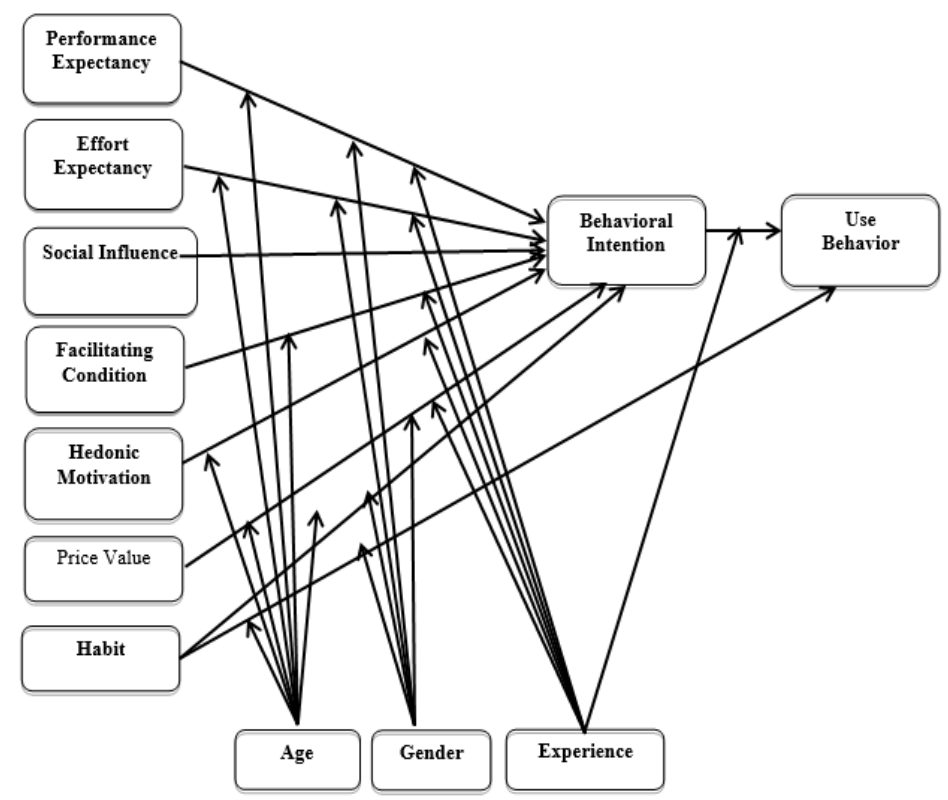

Figure 6. Unified Theory of Acceptance and Use of Technology 2 (UTAUT2)

(Source: Venkatesh et al., 2012)

UTAUT explains the influences of performance expectancy, effort expectancy, social influences, and facilitating conditions towards consumers' behavioural intentions to use drone food delivery services. These influences are moderated by demographic factors like gender, age, experience, and voluntariness of use (Venkatesh et al., 2003; Figure 5). Following this, the extended framework of UTAUT has been further developed with added factors like hedonic motivation, price value, and habit to reflect more consumer-oriented behaviours. Voluntariness factor was removed from the UTAUT2 with the assumption that consumers would not be forced to accept, buy, or use drone for food delivery services (Venkatesh et al., 2012; Figure 6).

\subsection{The Factors That Shaping Behavioural Intentions to Use Drone Delivery Services}

The use of drone delivery across various industries spiked as drone delivery increased the productivity and operational efficiencies (Avanti, 2019). It was also found to be useful in emergencies (CAA, 2016). Consumers aged from 18 to 34 were having positive perceptions towards these available drone food delivery services. Ostensibly, they perceived drone delivery as modern, futuristic, innovative, and useful, even though it was risky (CAA, 2016). For them, personal data-collection was an acceptable trade-off as long as the service benefits them (Dorsey, 2018). For instance, they get their purchased merchandise like food faster with drone delivery (Khan, 
2019). Positive reviews from the users increase the acceptability of drone delivery among consumers (Ramadan et al., 2017). Besides, consumers also saw drone delivery services as a relatively eco-friendlier option (Hwang et al., 2019).

\subsubsection{Functions}

The use of Drone was a convenient and efficient technology for delivery services as it shortened the delivery time to as low as 30 minutes and delivers the merchandise to consumer's doorstep, which in turn increased consumers' productivity and flexibility in daily life (Garliordi, 2019; Kapser and Abdelrahman, 2020; Kumar et al., 2017; Hwang et al., 2019). These benefits underpin the consumers' willingness to try drone food delivery services as it is a speedy, cost-effective, and an ecologically friendly option compared to other delivery methods (Kim, 2020; Stolaroff et al., 2018). Besides, drone delivery allowed merchants to customized and provide personalized services and/or products based on the customers' needs further galvanizing consumers' behavioural intentions towards drone delivery (Garliordi, 2019). For example, in Tanzania, a country located in the East Africa region, the people had higher behavioural intentions towards drone delivery as it allows them to receive the merchandise in remote areas that can be difficult to access by road (Saunders, 2019). Furthermore, usage of drone delivery surged during the novel Coronavirus, COVID-19 pandemic, which has sickened no less than 94,000 people around the world with a death toll of more than 3,200 , due to its innovative functions and usefulness in surveying, mapping, defence, surveillance, and logistics (Liu, 2020).

However, some factors had hindered consumers' behavioural intentions to use drone delivery. Firstly, consumers were unfamiliar with drone delivery as there was a lack of information about the service and hence, they needed time to learn about the advanced delivery services and the autonomy of flying function (Hwang et al., 2019). Secondly, a drone was unable to provide doorstep delivery due to long delivery distance and limitation in landing location. For examples, drone food delivery services provided by Uber and UPS where the drone dropped-off the merchandise at a safe location and used another mode of transport for the last mile delivery (Deagon, 2019; TheSun, 2019; Stewart, 2017). Thirdly, consumers were concerned about the security of drone delivery. The reason being each proprietary system was designed and developed independently by the respective company as there was no guideline for drone delivery systems, therefore, consumers' shipment and sensitive information would be insecure and vulnerable to exploitation by hackers if a weaker control system was adopted (Khan et al., 2019). Some other factors that decreased the consumers' behavioural intentions to use drone delivery were that it could not be used in heavy rain, unable to deliver heavy products beyond 800 grams of payload, and unable to deliver beyond 10 ten-mile radii (Ker, 2019; Insider, 2015). Aurambout et al. (2019) stated that only 7\% of consumers in developed countries like the United Kingdom, Germany, Italy, and France benefited from drone delivery services (Aurambout et al., 2019).

There was little evidence indicating consumers would obtain drone technologies for personal use as they did not know how to build, fly, land, repair, and upgrade the drone (Garrett and Anderson, 2018).

\subsubsection{Cost}

With cost-efficiency in mind, the cost of drone delivery affects consumers' behavioural intentions to use drone delivery services. Consumers would not pay to try out autonomous drone delivery services if it is more expensive, but would rather pursue other delivery options (Kapser and Abdelrahman, 2020; Hwang et al., 2019). However, Insider (2015) claimed that the price of drone delivery can be as low as 88 cents. This cost advantage is likely helpful to promote consumers' behavioural intentions to use drone for food delivery services as such technology enhances customer experiences, overall satisfaction, and engagement.

\subsubsection{Technology}

The attraction of drone technology was one of the factors that affect consumers' behavioural intentions to use drone food delivery services (Kapser and Abdelrahman, 2020; Hwang et al., 2019). New emerging technologies such as drone delivery improved the convenience, accessibility, and normative of retail. Besides, innovations also reduced time pressure, helped consumers in making good decisions, and even increased their confidence and satisfaction with their decision. All these have increased consumers' engagement and behavioural intentions to use drone delivery (Grewal et al., 2017).

However, consumers were concerned about the effectiveness of data processing in drone delivery. This is because the virtual remote control in drone delivery was basic when compared to the physical remote control and required advanced piloting skills and a large hardware controller. The Brain-Computer Interfaces (BCI) of drone delivery had poor manoeuvring precision and recognized only basic commands. The lack of precision consequently means the control system may fail to recognize the consumer targeted for delivery. This is further worsened by 
consumers' gestures that vary across different individuals and a voice control system which may lead to miscommunication (Alwateer et al., 2019). Moreover, payment processing was another issue in drone delivery as consumers were uncertain whether cash-on-delivery and/or mobile wallets were available upon delivery or otherwise. Aside from that, consumers were also worried about the security of their credit card and personal information when processing payment through the drone; they would rather process the payment online before the delivery (Khan et al., 2019).

\subsubsection{Human Factor}

The outbreak of COVID-19 has pushed society and the government to reconsider, understand, and utilize drone innovation. Drone developers have modified the software and equipped drones with a thermal camera for basic diagnostic functions, crowd management, and disinfectants dispersing (Liu, 2020; Jakhar, 2020). However, drone delivery was burdening consumers as they were unfamiliar with its operations, functions, and traffic characteristics (Alwater et al., 2019).

\subsubsection{Hedonic Motivation}

Positive hedonic motivation will increase consumers' behavioural intentions to use drone delivery services. There were a few factors that contribute to positive hedonic motivation. First, people deemed drone delivery services as an environmental-friendly option as the drone powered by a rechargeable battery may reduce the greenhouse gas emission and energy consumption per package (Stolaroff et al., 2018; Hwang and Kim, 2019; Kapser and Abdelrahman, 2020). Second, compared to physical remote control, the virtual remote control received feedback through a video feed, the BCI system allowed hands-free control and interaction with consumers through gestures recognition, and the voice control system of drone delivery created excitement and enjoyment to consumers' life (Alwateer et al., 2019; Hwang and Kim, 2019; Kapser and Abdelrahman, 2020). Third, the positive image portrayed by media and marketers that drones are good for civilian applications, for example, a device for personal enjoyment and parcel delivery (Mosco and Mosco, 2017). Fourth, during exceptional events like the COVID-19 outbreak, people are fearful and concerned about close contact with others, drone delivery offers a safe and low-risk option to the consumers ( $\mathrm{Hu}, 2020)$.

Conversely, some factors contributed to negative hedonic motivation like lack of security and peace of mind, which decreased consumers' behavioural intentions to use drone delivery (Chang et al. 2017; Hwang and Choe, 2019; Alwateer et al., 2019). For instance, consumers were anxious and worried about the possibility that they may not be able to interact effectively with the drone technology like opening the locker and collecting their food (Kapser and Abdelrahman, 2020; Jackman, 2019). Besides, the safety of drone delivery was also a concern in that it may lose control, cause road accident or mid-air collision and results in injuries, interfere with the aircraft traffic, or inability to detect and avoid the surrounding objects (Alwateer et al., 2019; Kapser and Abdelrahman, 2020; Jackman, 2019). Also, consumers were unsure whether or not the drone was associated with rogue, nuisance, nefarious, unlawful, disobedient, abuse, protest, risky, and unsafe activities, and felt risky about its use (Jackman, 2019). Furthermore, the fact that drone has been used in the military for aerial surveillance, drone strikes, drone weapon delivery, reconnaissance, troop management, etc. has caused unease among consumers (Luhan, 2013; Mosco and Mosco, 2017). In short, consumers were disturbed and have developed unpleasant feelings towards drone delivery due to all these factors and as a result, hindered their behavioural intentions to try drone for food delivery services (Joshi, 2019).

\subsubsection{Security}

Security was another factor that affects consumers' behavioural intentions to use drone food delivery services as consumers were less likely to try drone delivery if it was risky (Kapser and Abdelrahman, 2020; Hwang et al., 2019).

As the drone was outfitted with a camera and facial recognition software capable of targeting specific people, spy, and collect data, consumers were worried their privacy may be compromised and misused especially when there was a lack in rules to control drone use (Ziman, 2018; Khan et al., 2019). Besides, there was also a possibility that the drone may crash into a person, pet, or property at the landing site, hence reducing consumers' behavioural intentions to try drone delivery (McFarland, 2019).

\subsubsection{Cognition}

Consumers' cognition toward drone delivery affects their behavioural intentions to use the service. Before deciding to use, they would first take various aspects of the service into account, and logically consider and evaluate the advantages and disadvantages of using the service (Kapser and Abdelrahman, 2020; Hwang et al., 2019). 
Evidence suggests consumers found difficulties in understanding the drone delivery systems when the systems and algorithms used in drones were evolving at a rapid pace towards better drone delivery systems. Besides, consumers could not effectively evaluate the drone delivery services provided by different companies because of the proprietary nature of individual systems and designs adopted by each company (CBI, 2020; TheSun, 2019). Alwateer et al. (2019) stated that the delivery drones were not installed with software for safety and security measures. For examples, B4UFLY which checks for the allowable flying zones and Geofencing which programs a drone to fly within pre-defined virtual tunnels to keep out of the no-fly zone and to avoid flying hazardously. Despite traffic management in place and drone registration requirement from traffic authority, the authority was unable to detect and seize illegal drone. There were still issues in the rules, land rights, and jurisdiction on drone delivery (Chang et al., 2017; Alwateer et al., 2019). At the core of the many challenges, drone delivery services were falling short of consumers' expectations in service quality and user experience as there were still many issues to be resolved such were energy consumption, monetary costs, data transmission efficiency, and data analysis (Alwateer et al., 2019).

\subsubsection{Regulation}

Consumers' behaviour intentions to use drone food delivery services were affected by regulations as well (Kapser and Abdelrahman, 2020; Hwang et al., 2019). Authorities like FAA and European Aviation Safety Agency started to develop regulations to encourage positive outcomes from commercial drones as soon as the idea of commercial drones emerged. At this stage, when the regulations were still developing, the consumer's behaviour intentions to use drone delivery services remained low (Stolaroff et al., 2018). While other countries were still considering drone delivery, the government of Tanzania has already reformed its regulations and launched fully automated drone delivery in early 2018 . Hence the reason why the consumers' behavioural intentions to use drone delivery services was higher in Tanzania (McFarland, 2017).

Complex drone regulations, such as those in Malaysia, are common challenges that hinder positive consumers' behavioural intentions to try drone for food delivery services. The vice-president of enterprise development of the Malaysia Digital Economy Corporation (MDEC) stated favourably that they will continue to implement adaptive regulations and policies, develop talents and skills, increase public awareness and improve enterprise adoption of drone delivery, and encourage strategic partnerships to promote drone food delivery services (Avanti, 2019). There were no regulations that govern the architecture composition of drone services and servers, therefore, substantial changes would be required whenever new drones are being added into the drone server systems, which will then lead to rigidness in an airborne fog computing infrastructure that disturbs data management and scales down drone delivery operations (Alwater et al., 2019).

\subsubsection{Land Rights and Jurisdiction}

Land rights and jurisdiction for drone delivery would affect consumers' behavioural intentions to use drone food delivery services as well (Kapser and Abdelrahman, 2020; Hwang et al., 2019).

Commercial use of drone and consumers' behavioural intentions to use drone delivery were discouraged by issues such as lack of designated airways, warehouse spaces and landing spaces for drone delivery drop-off and parcel loading, especially when it involves large-size drone delivery in city areas where landing in consumers' backyards may be deemed as invading their private territory (Yurieff, 2017; Stolaroff et al., 2018; McFarland, 2019).

\subsubsection{Social}

The social benefits of drone delivery will affect consumers' behavioural intentions to use drone food delivery services. For example, early adopters of drone technology have the first movers appeal on others, stand out in a crowd, and/or become the thought leaders in their field (Kapser and Abdelrahman, 2020; Hwang et al., 2019).

In October 2019 when drone delivery was still in its early stages of development, FedEx Corporation offered the drone food delivery service to their customers. In so doing, consumers were able to send sweets and treats to their friends and family (Sakharkar, 2019). However, such drone delivery was limited to short-distance delivery (The WiredShopper, 2019). Not to be disenfranchised by the opportunity, those who were connected to friends or family using drone delivery service were influenced and nudged towards giving the service a try. Otherwise, the likelihood for them to use the service remained low as they will not dispense extensive time on research to learn about drone technology (CAA, 2016). 


\subsection{The Conceptual Framework}

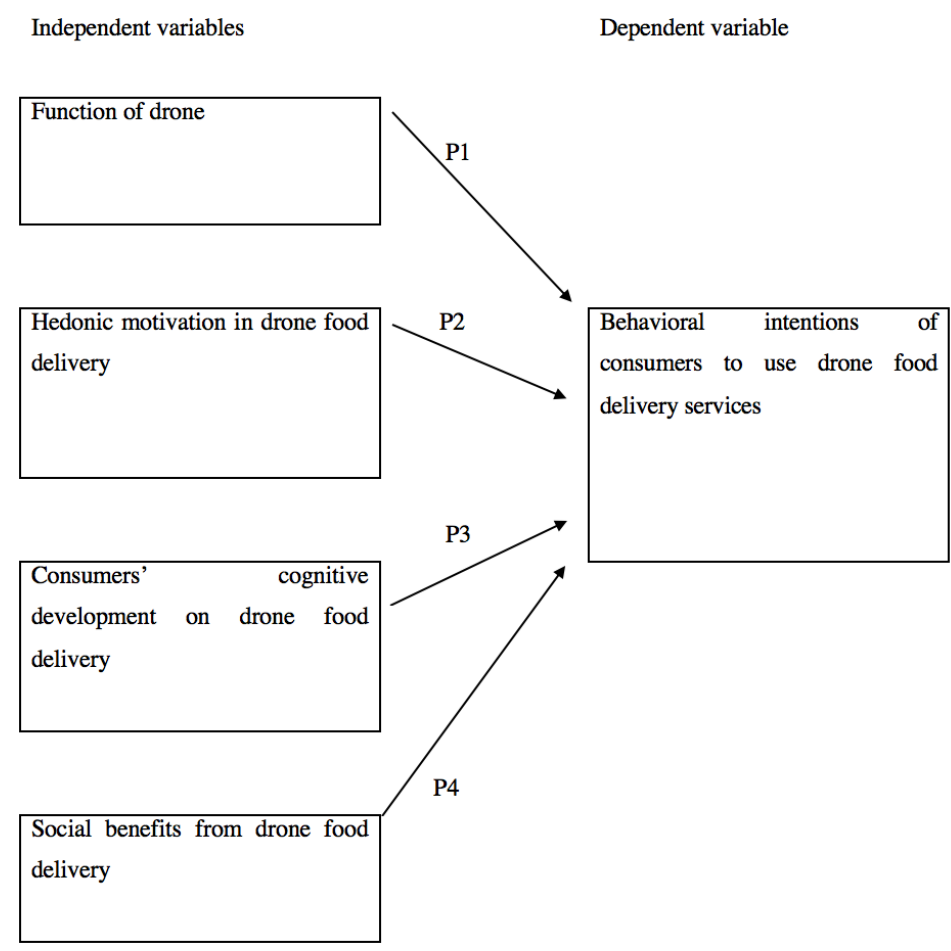

Figure 7. The proposed conceptual framework

(Source: Adopted from Kapser and Abdelrahman, 2020; Hwang et al., 2019)

Based on research findings and news that related to consumers' behavioural intentions to use drone as food delivery services, this study has proposed to adopt the frameworks from Kapser and Abdelrahman (2020) and Hwang et al. (2019) and formed the following propositions:

P1: Functions of a drone will affect consumers' behavioural intentions to use drone food delivery services

P2: Hedonic motivation in drone delivery will affect consumers' behavioural intentions to use drone food delivery services

P3: Consumers' cognition toward drone delivery will affect consumers' behavioural intentions to use drone food delivery services

P4: Social benefits of drone delivery will affect consumers' behavioural intentions to use drone food delivery services

The proposed conceptual framework in Figure 7 was to answer the research problem on why the drone is another technology that is not ready to take off. It shows the four main independent variables, which are functions, hedonic motivation, cognition, and social factors, that affect the dependent variable, which is the consumers' behavioural intentions to use drone food delivery services.

\subsubsection{Justification for Using the Framework from Kapser and Abdelrahman (2020) and Hwang et al. (2019)}

Both Kapser and Abdelrahman (2020) and Hwang et al. (2019) studied the factors that affect consumers' behavioural intentions to use drone food delivery services, however, the independent variables involved in their proposed research framework and research outcomes were different from each other. The past studies and news showed that consumers' behavioural intentions to use drone food delivery services were affected by drone functions, which do not benefit consumers, hedonic motivation. consumers' cognition, and social benefits of drone delivery (Alwateer et al., 2019; Khan et al., 2019; Alwater et al., 2019; Aurambout et al., 2019; Kapser and Abdelrahman, 2020; Jackman, 2019; Luhan, 2013; Avanti, 2019; CBI, 2020; TheSun, 2019; TheWiredShopper, 2019; CAA, 2016). The framework of Kapser and Abdelrahman (2020) was adopted in this study to complement the framework of Hwang et al. (2019) to cover all the stipulated variables. 


\subsection{Contribution of the Study}

Businesses relied on consumers' behavioural intentions analysis to increase revenue and customer engagement, trust, and loyalty on drone delivery services (Kumar, 2017; Zwickle et al., 2019). While the government relied on the analysis of consumers' behavioural intentions to use drone delivery services to advance the technologies and economic activities in the country (Avanti, 2019; McFarland, 2017; Dost and Maier, 2018).

\subsection{Knowledge Gaps and Research Outcomes}

Chang et al. (2017) stated that the reason why the regulations focusing on consumers' privacy and security when using drone delivery have been minimal was due to the low awareness of privacy and security among the users. In contrast, Zwickle et al. (2019) stated that the lack of regulations that focus on privacy and security to protect consumers when using drone delivery was due to the large discrepancy in consumers' preferences for legal protection on personal privacy.

Kapser and Abdelrahman (2020) found that price was the strongest predictor for consumers' behavioural intentions to use drone food delivery services, followed by performance expectancy, which includes functions and usefulness of drone delivery, hedonic motivation, perceived risk, social influences, and facilitating conditions. In contrast, Hwang et al., (2019) stated that consumers' behavioural intentions to use drone delivery services were most influenced by the drone's innovative functions, and to a lesser extent, by hedonic motivation, cognition, and social benefits.

The independent variables that were not included in the framework of Hwang et al. (2019) were covered by adopting the framework of Kapser and Abdelrahman (2020). Empirical findings from journals and news on authorized websites indicated that the reason why drone delivery is another tech idea not ready to take off was that the consumers' behavioural intentions to use drone delivery services were not in the state of technological readiness as demonstrated by weakness in drone delivery functions and also in hedonic motivation, cognition, and social benefits.

\section{Conclusion}

\subsection{Overview of the Study}

The objective of this study was to study why drone delivery is another tech idea not ready to take off. Based on research findings and news related to consumers' behavioural intentions to use drone food delivery services, conceptual frameworks have been proposed to show the four main independent variables, which are functions, hedonic motivation, cognition, and social factors, that affect the dependent variable, which is behavioural intentions of consumers to use drone as food delivery services. However, it was difficult to justify the proposed conceptual frameworks due to the contradicting findings in past studies. Overall, factors that were prohibiting consumers' behavioural intentions to use drone food delivery services were consumers' unfamiliarity and negative perceptions toward drone delivery in that it is unregulated, dangerous, risky, lack of quantified risk assessments, intimidating, related to military and defence, and lengthy in the process to obtain authority's permission to operate drone delivery. Nevertheless, they may be influenced to use drone delivery if their friends and family were using it.

\subsection{Implications and Recommendations}

This study has answered the research problem by adopting the frameworks from Hwang et al. (2019) and Kapser and Abdelrahman (2020). TAM supported the proposed conceptual framework and showed that drone's functions, hedonic motivation, cognition, and social benefits could positively influence consumers' behavioural intentions or attitudes in using innovations like drone delivery especially when consumers realized the ease of use and usefulness of drone delivery (Venkatesh and Davis, 2000).

TPB supported the proposed conceptual framework by showing that consumers' intentions to use drone delivery were positively influenced by drone's functions, hedonic motivation, cognition, and social benefits when there were positive attitudes in consumers, positive subjective norms like friends and family, and perceived behavioural control in consumers (Khan et al., 2019).

Lastly, UTAUT supported the proposed conceptual framework by showing that consumers' intentions to use drone delivery were positively influenced by drone's functions, hedonic motivation, cognition, and social benefits such as performance expectancy, social influences, and facilitating conditions (Venkatesh et al., 2003).

Promoting consumers' behavioural intentions in using drone delivery services brought benefits like an increase in resource efficiency and effectiveness, productivity, and flexibility, environment preservation, excitement and entertainment, and technology and economic development (Kapser and Abdelrahman, 2020; Hwang et al., 2019). 
To promote consumers' behaviour intentions in using drone delivery, food companies have been participating in the development of drone and applying for permits from traffic authorities like the FAA to operate and offer drone delivery services. While the government has set out new regulations to encourage the development of drone technology.

The findings in this study were based on the secondary data obtained from the literature review. Future studies may consider collecting primary data from both drone delivery users and those who never use drone delivery to study the relationship between behavioural intentions and usage behaviours in drone delivery. This enables merchants to increase customer engagement and better cater to the needs and wants of consumers.

\section{Acknowledgement}

I am grateful for the opportunity to write about a subject nestled at the intersection of technology and business. The experience gained in the writing this paper has been rewarding and personally fulfilling. Many thanks to my family and friends who have tolerated mundane discussions around topics such as this and my parents who are most patient in reading my work.

\section{References}

Ajzen, I. (1991). The Theory of Planned Behaviour. Organizational Behaviour and Human Decision Processes, 50(2), 179-211. https://doi.org/10.1016/0749-5978(91)90020-T

Alwateer, M., Loke, S. W., \& Zuchowicz, A. M. (2019). Drone services: issues in drones for location-based services from human-drone interaction to information processing. Journal of Location-based Services, 13(2), 94-127. https://doi.org/10.1080/17489725.2018.1564845

Associated Press. (2019). Walgreens, Google affiliate to test drone deliveries. [online]. Retrieved February 19, 2020, from https://fox2now.com/2019/09/19/walgreens-google-affiliate-to-test-drone-deliveries/

Aurambout, J., Gkoumas, K., \& Ciuffo, B. (2019). Last-mile delivery by drones: an estimation of viable market potential and access to citizens across European cities. European Transport Research Review, 11(1), 1-21. https://doi.org/10.1186/s12544-019-0368-2

Avanti, K. (2019). Drone tech and the roar of Malaysia's flying dragons. [online]. Retrieved February 19, 2020, from https://www.computerweekly.com/news/252466404/Drone-tech-and-the-roar-of-Malaysias-flying-dragons

CAA. (2016). Consumer drone users. [online]. Retrieved February 19, 2020, from https://dronesafe.uk/wp-content/uploads/2016/11/CAA_Consumer_Drone_Users_report.pdf

CBI. (2020). From Retailers To Insurance Providers, Here Are 21 Corps Using Drone Tech Today. [online]. Retrieved February 19, 2020, from https://www.cbinsights.com/research/report/corporations-drone-technology/\#bechtel

Chan, R. (2019). A drone attack at a Saudi Arabia airport killed one person and wounded seven people. [online]. Retrieved February 19, 2020, from https://www.businessinsider.my/houthi-attack-abha-airport-saudi-arabia-2019-6/

Chang, V., Chundury, P., \& Chetty, M. (2017). Spiders in the Sky: User Perceptions of Drones, Privacy, and Security. ACM, 6765. https://doi.org/10.1145/3025453.3025632

Chawinga, W., \& Zinn, S. (2016). Use of Web 2.0 by students in the Faculty of Information Science and Communications at Mzuzu University, Malawi. https://doi.org/10.4102/sajim.v18i1.694

Davis, F. D., Bogozzi, R. P., \& Warshaw, P. R. (1989). User acceptance of computer technology: A comparison of two theoretical models. Management Science, 35, 982-1003. https://doi.org/10.1287/mnsc.35.8.982

Deagon, B. (2019). Food Delivery Apps Are In A Race For Orders, Putting Uber And Grubhub Stock On Defensive. [online]. Retrieved February 19, 2020, from https://www.investors.com/news/technology/grubhub-stock-uber-stock-defensive-food-delivery-apps-race-c onsumer-orders/

Dejonghe, F. (2019). Drone Technology Readiness And Adoption In The Construction And Surveying Industry. [online]. Retrieved from https://lib.ugent.be/fulltxt/RUG01/002/784/387/RUG01-002784387_2019_0001_AC.pdf

Dilanian, K., \& Kube, C. (2020). Airport informants, overhead drones: How the U.S. killed Soleimani. [online]. Retrieved February 19, 2020, from 
https://www.nbcnews.com/news/mideast/airport-informants-overhead-drones-how-u-s-killed-soleimani-n11 13726

Dorsey, S. (2018). They Are Watching You: Drones, Data \& the Unregulated Commercial Market. Federal Communications Law Journal, 70(3), 351-VII.

Dost, F., \& Maier, E. (2018). "E-Commerce Effects on Energy Consumption: A Multi-Year Ecosystem-Level Assessment. Journal of Industrial Ecology, 22(4), 799-812. https://doi.org/10.1111/jiec.12639

Elliott, A. (2019). Automated mobilities: From weaponized drones to killer bots. Journal of Sociology, 55(1), 20-36. https://doi.org/10.1177/1440783318811777

FAA. (2020). Package Delivery by Drone (Part 135). [online]. Retrieved February 19, 2020, from https://www.faa.gov/uas/advanced_operations/package_delivery_drone/

Gagliordi, N. (2019). UPS completes first residential drone deliveries from a CVS Pharmacy. [online]. Retrieved February 19, 2020, from https://www.zdnet.com/article/ups-completes-first-residential-drone-deliveries-from-a-cvs-pharmacy/

Garrett, B., \& Anderson, K. (2018). Drone methodologies: Taking flight in human and physical geography. Transactions of the Institute of British Geographers, 43(3), 341-359. https://doi.org/10.1111/tran.12232

Grewal, D., Roggeveen, A. L., \& Nordfält, J. (2017). The Future of Retailing. Journal of Retailing, 93(1), 1-6. https://doi.org/10.1016/j.jretai.2016.12.008

$\mathrm{Hu}, \mathrm{M} . \mathrm{H}$. (2020). China's e-commerce giants deploy robots to deliver orders amid coronavirus outbreak. [online]. Retrieved February 19, 2020, from https://www.techinasia.com/chinas-ecommerce-robots-delivery

Hwang, J., \& Choe, J. Y. (2019). Exploring perceived risk in building successful drone food delivery services. International Journal of Contemporary Hospitality Management, 31(8), 3249-3269. https://doi.org/10.1108/IJCHM-07-2018-0558

Hwang, J., \& Kim, H. (2019). Consequences of a green image of drone food delivery services: The moderating role of gender and age. Business Strategy and the Environment, 28(5), 872-884. https://doi.org/10.1002/bse.2289

Hwang, J., Cho, S., \& Kim, W. (2019). Consequences of psychological benefits of using eco-friendly services in the context of drone food delivery services. Journal of Travel \& Tourism Marketing, 36(7), 835-846. https://doi.org/10.1080/10548408.2019.1586619

Hwang, J., Kim, H., \& Kim, W. (2019). Investigating motivated consumer innovativeness in the context of drone food delivery services. Journal of Hospitality and Tourism Management, 38, 102-110. https://doi.org/10.1016/j.jhtm.2019.01.004

Hwang, J., Lee, J., \& Kim, H. (2019). Perceived innovativeness of drone food delivery services and its impacts on attitude and behavioural intentions: The moderating role of gender and age. International Journal of Hospitality Management, 81, 94-103. https://doi.org/10.1016/j.ijhm.2019.03.002

Jackman, A. (2019). Consumer drone evolutions: trends, spaces, temporalities, threats. Defense \& Security Analysis, 35(4), 362-383. https://doi.org/10.1080/14751798.2019.1675934

Jakhar, P. (2020). Coronavirus: China's tech fights back. [online]. Retrieved February 19, 2020, from https://www.bbc.com/news/technology-51717164

Joshi, D. (2019). Drone technology uses and applications for commercial, industrial and military drones in 2020 and the future. [online]. Retrieved February 19, 2020, from https://www.businessinsider.com/drone-technology-uses-applications?IR=T

Kapser, S., \& Abdelrahman, M. (2020). Acceptance of autonomous delivery vehicles for last-mile delivery in Germany - Extending UTAUT2 with risk perceptions. Transportation Research Part C, 111, $210-225$. https://doi.org/10.1016/j.trc.2019.12.016

Kelso, A. (2019). Food Delivery Via Drones May Be Closer Than You Think. [online]. Retrieved February 19, 2020, from https://www.forbes.com/sites/aliciakelso/2019/07/12/food-delivery-via-drones-may-be-closer-than-you-thin $\mathrm{k} / \# 76 \mathrm{f} 9569 \mathrm{~d} 7438$

Ker, N. (2019). Malaysians will see drone food delivery trials by end of June. [online]. Retrieved February 19, 2020, from https://www.soyacincau.com/2019/06/18/drone-tech-food-delivery-cyberjaya/ 
Khan, R., Tausif, S., \& Javed Malik, A. (2019). Consumer acceptance of delivery drones in urban areas. International Journal of Consumer Studies, 43(1), 87-101. https://doi.org/10.1111/ijcs.12487

Kim, A. (2020). Uber may soon deliver Big Macs to you by drone. [online]. Retrieved February 19, 2020, from https://edition.cnn.com/2019/06/12/tech/uber-eats-elevate-food-drone-delivery-trnd/index.html

Kumar, V., Anand, A., \& Song, H. (2017). Future of Retailer Profitability: An Organizing Framework. Journal of Retailing, 93(1), 96-119. https://doi.org/10.1016/j.jretai.2016.11.003

Kumar, V., Rajan, S. G., \& Pozza, I. D. (2019). Customer engagement in service. Journal of the Academy of Marketing Science, 47(1), 138-160. https://doi.org/10.1007/s11747-017-0565-2

Lai, P. C. (2017). The literature review of technology adoption models and theories for the novelty technology. Journal of Information Systems and Technology Management, 14(1), 21-38. https://doi.org/10.4301/S1807-17752017000100002

Liu, Y. J. (2020). China adapts surveying, mapping, delivery drones to enforce world's biggest quarantine and contain COVID-19 outbreak. [online]. Retrieved February 19, 2020, from https://www.thestar.com.my/tech/tech-news/2020/03/05/china-adapts-surveying-mapping-delivery-drones-t o-enforce-worlds-biggest-quarantine-and-contain-covid-19-outbreak

Luhan, V. (2013). The New Guantanamo”: The psychological impact of US drone strikes in Pakistan. [online] E-International Relations. [online]. Retrieved February 19, 2020, from https://www.eir.info/2015/05/16/the-new-guantanamo-the-psychological-impact-of-us-drone-strikes-in-pakistan/

Mark, R. (2019). UPS and CVS Complete First Residential Drone Deliveries. [online]. Retrieved February 19, 2020, from https://www.flyingmag.com/story/news/ups-cvs-drone-deliveries/

McFarland, M. (2017). East Africa is leading the world in drone delivery. [online]. Retrieved February 19, 2020, from https://money.cnn.com/2017/08/24/technology/east-africa-drones/index.html

McFarland, M. (2019). This Alphabet-owned company is delivering espresso via drone in Australia. [online]. Retrieved February 19, 2020, from https://edition.cnn.com/2019/04/09/tech/alphabet-drone-delivery/index.html

Mosco, V., \& Mosco, V. (2017). After the Internet: New Technologies, Social Issues, and Public Policies. Fudan Journal of the Humanities and Social Sciences, 10(3), 297-313. https://doi.org/10.1007/s40647-016-0156-5

Pillai, V. (2019). Experts split on whether food delivery by drone will take off. [online]. Retrieved February 19, 2020 , from

https://www.freemalaysiatoday.com/category/nation/2019/06/24/experts-split-on-whether-food-delivery-bydrone-will-take-off/

Ramadan, Z. B., Farah, M. F., \& Mrad, M. (2017). An adapted TPB approach to consumers' acceptance of service-delivery drones. Technology Analysis \& Strategic Management, 29(7), 817-828. https://doi.org/10.1080/09537325.2016.1242720

Royer, D. (2019). FedEx launches first drone delivery trial. [online]. Retrieved February 19, 2020, from https://wreg.com/2019/10/18/fedex-launches-first-drone-delivery-service/

Royo-Vela, M., \& Black, M. (2020). Drone images versus terrain images in advertisements: Images' verticality effects and the mediating role of mental simulation on attitude towards the advertisement. Journal of Marketing Communications, 26(1), 21-39. https://doi.org/10.1080/13527266.2018.1425896

Saunders, J. (2019). UPS seeks FAA OK for new drone delivery division. [online]. Retrieved February 19, 2020, from https://www.bizjournals.com/atlanta/news/2019/07/24/atlanta-based-ups-seeks-faa-ok-for-new-drone.html

Scutti, S. (2019). First drone delivery of a donated kidney ends with successful transplant. [online]. Retrieved February 19, 2020, from https://edition.cnn.com/2019/05/01/health/drone-organ-transplant-bn-trnd/index.html

Statista. (2018). Drone Delivery for Retail: Statistics and Facts. [online]. Retrieved February 19, 2020, from https://www.statista.com/topics/3284/drone-delivery-for-consumer-goods/

Stewart, J. (2017). A Drone-Slinging UPS Van Delivers the Future. [online]. Retrieved February 19, 2020, from https://www.wired.com/2017/02/drone-slinging-ups-van-delivers-future/

Stolaroff, J. K., Samaras, C., O'Neill, E. R., Lubers, A., Mitchell, A. S., Ceperley, D., \& Lawrence Livermore 
National Lab. (LLNL), Livermore, CA (United States). (2018). Energy use and life cycle greenhouse gas emissions of drones for commercial package delivery. Nature Communications, 9(1), 409-13. https://doi.org/10.1038/s41467-017-02411-5

Stradling, R. (2019). WakeMed in Raleigh is the spot as UPS makes its first deliveries with drones in the U.S. [online]. Retrieved February 19, 2020, from https://www.newsobserver.com/news/local/article228373214.html

Taylor, S., \& Todd, P. A. (1995). Understanding information technology usage: A test of competing models. Information Systems Research, 6(2), 144-176. https://doi.org/10.1287/isre.6.2.144

The WiredShopper. (2019). Flytrex Drone Delivers Lunch. [online]. Retrieved February 19, 2020, from https://thewiredshopper.com/flytrex-drone/

TheGuardian. (2020). Trump claims Suleimani was 'saying bad things' about US before deadly strike. [online]. Retrieved February 19, 2020, from https://www.theguardian.com/us-news/2020/jan/18/trump-suleimani-iran-drone-strike

TheSun. (2019). Uber to use drones for food delivery, unveils new autonomous car. [online]. Retrieved February 19,2020 , from https://www.thesundaily.my/world/uber-to-use-drones-for-food-delivery-unveils-new-autonomous-car-DI96 5445

Venkatesh, V., \& Davis, F. (2000). A Theoretical Extension of the Technology Acceptance Model: Four Longitudinal Field Studies. Management Science, 46(2), 186-204. https://doi.org/10.1287/mnsc.46.2.186.11926

Venkatesh, V., Morris, M. G., Davis, G. B., \& Davis, F. D. (2003). User acceptance of information technology: Toward a unified view. MIS Quarterly, 27(3), 425-478. https://doi.org/10.2307/30036540

Venkatesh, V., Thong, J. Y. L., \& Xu, X. (2012). Consumer Acceptance and Use of Information Technology: Extending the Unified Theory of Acceptance and Use of Technology. MIS Quarterly, 36(2), 157-178. https://doi.org/10.2307/41410412

Yurieff, K. (2017). Amazon patent reveals drone delivery 'beehives'. [online]. Retrieved February 19, 2020, from https://money.cnn.com/2017/06/23/technology/amazon-drone-beehives/index.html

ZimAn, K. (2018). Privacy in Plain Sight: Fourth Amendment Considerations for the Collection, Retention, and Use of Data, Homeland Security Affairs.

Zwickle, A., Farber, H. B., \& Hamm, J. A. (2019). Comparing public concern and support for drone regulation to the current legal framework. Behavioural Sciences \& the Law, 37(1), 109-124. https://doi.org/10.1002/bsl.2357

\section{Copyrights}

Copyright for this article is retained by the author(s), with first publication rights granted to the journal.

This is an open-access article distributed under the terms and conditions of the Creative Commons Attribution license (http://creativecommons.org/licenses/by/4.0/). 